\title{
The incidence and management of hypotension in the pregnant parturients undergoing caesarean section following spinal anaesthesia with $0.5 \%$ bupivacaine
}

\author{
Shashi Dinkar Minj ${ }^{1}$, Rameshwari Beck ${ }^{2 *}$, Ajit Kumar ${ }^{3}$, Praveen Tiwari ${ }^{3}$, \\ Raj Kumar Chandan ${ }^{1}$, Sukanta Sen ${ }^{4}$
}

\begin{abstract}
${ }^{1}$ Department of Anaesthesiology, ${ }^{2}$ Department of Obstetrics and Gynecology, ICARE Institute of Medical Sciences and Research, Haldia, West Bengal, India

${ }^{3}$ Department of Obstetrics and Gynecology, Rajendra Institute of Medical Sciences, Ranchi, Jharkhand, India

${ }^{4}$ Department of Pharmacology, ICARE Institute of Medical Sciences and Research, Haldia, West Bengal, India
\end{abstract}

Received: 24 December 2017

Accepted: 24 January 2018

\section{*Correspondence:}

Dr. Rameshwari Beck,

E-mail: drrbeck1980@gmail.com

Copyright: ( $)$ the author(s), publisher and licensee Medip Academy. This is an open-access article distributed under the terms of the Creative Commons Attribution Non-Commercial License, which permits unrestricted non-commercial use, distribution, and reproduction in any medium, provided the original work is properly cited.

\begin{abstract}
Background: Spinal anesthesia for cesarean section is not a $100 \%$ successful technique. At times, despite straightforward insertion and drug administration, intrathecal anaesthesia for cesarean section fails to obtain any sensory or motor block.

Methods: This study is aimed at comparing the incidence of hypotension and the need for vasopressors in patients submitted to caesarean section under spinal anaesthesia following preload with either crystalloid or colloid. This study was carried out on 100 healthy pregnant women with single term foetus and not in labor admitted at the labor room of Gynecological department of RIMS. Blood pressure, Pulse rate, $\mathrm{O}_{2}$ Saturation and episodes of hypotension were recorded every 5 minutes from the spinal block.

Results: The study showed that maximum number of caesarean sections here performed for the indication of foetal distress which is seen in 44\%, 48\%, 52\%, and 48\% in Group A, Group B, Group C and Group D respectively. This is followed by scar tenderness and obstructed labour. In Group A maximum number of patients developed hypotension during 11-20 minutes duration which is $13(61.9 \%)$ followed by $5(23.8 \%)$ patients during first 10 minutes.

Conclusions: The study concludes that the combined use of volume preloading to compensate for vasodilatation and vasopressor to counteract arterial dilatation is a very effective method in reducing the incidence, severity and duration of spiral hypotension. The combination group with decreased volume of preload and reduced dose of vasoconstrictor provides better haemodynamic stability when compared to preloading of vasoconstrictors alone.
\end{abstract}

Keywords: Bupivacaine, Caesarean section, Cardiovascular effects, Parturient, Spinal anaesthesia

\section{INTRODUCTION}

The practice of regional anaesthesia for caesarean section is common place today in developed countries like the USA and the UK, and is gradually increasing in developing countries. ${ }^{1,2}$ It involves the use of epidural or spinal anaesthesia which allows consciousness during the operation. ${ }^{3,4}$ Spinal anaesthesia is preferred over epidural anaesthesia for elective caesarean and emergency caesarean procedures, due to the relative ease of administration, reduced systemic toxicity, faster onset of action and start of the operation. ${ }^{1,4,5}$ Spinal anaesthesia, 
also known as a spinal or subarachnoid block, involves an injection of local anaesthetic drugs into the spinal space containing cerebrospinal fluid and surrounding nerves that supply the abdomen and uterus using a spinal needle. ${ }^{3}$ Spinal block is administered at L3 to L4 level of the subarachnoid space, thus allowing independent control of respiratory function. ${ }^{5}$ Administration of spinal anaesthesia induces a blockade of neuronal signals supplying the abdomen and uterus at level T6 to T10., In the subarachnoid space, the distribution of drugs used for spinal blockade is affected by the inherent characteristics of the anaesthetic, the patient, spinal fluid, and the injection technique of the anaesthetist. ${ }^{7,8}$

Cardiovascular effects during spinal anaesthesia are almost entirely due to the fact that the local anaesthesia, like $0.5 \%$ heavy bupivacaine, injected into the subarachnoid space not only blocks somatic, sensory and motor fibres, but also produces preganglionic sympathetic blockade. Depending on the intensity and extent of preganglionic sympathetic blockade, blood pressure and heart rate may be affected by several mechanisms. $^{9}$

The characteristics of an ideal spinal anaesthetic agent in day care setting would include a rapid onset of a reliable block providing adequate surgical anaesthesia of appropriate duration, rapid recovery of sensory and motor block and minimal side-effects. ${ }^{10}$

The local anaesthetic agents available for spinal anaesthesia in day care surgery include lignocaine, bupivacaine, levobupivacaine and ropivacaine may cause decrease in arterial tone, decrease in preload, slowing of heart rate and decrease in cardiac contractility. It is important to bear in mind the other possible causes of a low blood pressure in the parturients in the presence of neuraxial block: haemorrhage, aortocaval compression, excessive sympathetic blockade, intravascular injection of local anaesthetic, anaphylaxis, embolism and vasovagal episode. ${ }^{9}$

This study was aimed at comparing the incidence of hypotension and the need for vasopressors in patients submitted to caesarean section under spinal anaesthesia following preload with either crystalloid or colloid.

\section{METHODS}

This study was carried out on 100 healthy pregnant women with single term foetus and not in labor admitted at the labor room of Gynaecological department of RIMS, Ranchi between the periods of eight months after taking institutional ethics committee permission and individual informed written consent. Only emergency Obstetrical cases ASA grade I and grade II were included in this study. Selected patients were randomly divided into four groups of 25 each depending upon whether they received crystalloids (Group A), colloids (Group B), crystalloids with vasopressor (Group C) or colloids with vasopressor (Group D).

\section{Group A: crystalloid group}

Patients of this group were given 20-25 ml/kg of crystalloid at the maximum infusion rate 5 minutes before induction of spinal anaesthesia till the end of operation.

\section{Group B: colloid group}

Patients of this group were given $10-15 \mathrm{ml} / \mathrm{kg}$ of colloid at the maximum infusion rate 5 minutes before induction of spinal anaesthesia till the end of operation.

\section{Group C: crystalloid and vasopressor group}

Patients of this group were given $20-25 \mathrm{ml} / \mathrm{kg}$ of crystalloid at the maximum infusion rate, 5 minutes preceding the induction of spinal anaesthesia followed by addition of $10 \mathrm{mg}$ of ephedrine in the I.V. drip.

\section{Group D: colloid and vasopressor group}

Patients of this group were given $10-15 \mathrm{ml} / \mathrm{kg}$ preceding the induction of spinal anaesthesia followed by addition of $10 \mathrm{mg}$ ephedrine in the I.V. drip.

\section{Exclusion criteria}

Exclusion criteria includes patients refusal, obesity, height $(<152 \mathrm{~cm})$, pregnancy induced hypertension, chronic hypertension, heart disease, multiple gestation, age $<18$ or $>40$ years, systolic blood pressure $<100 \mathrm{~mm}$ hg, total or partial spinal anaesthesia failure and fasting for less than 6 hours.

The patients selected were subjected to a thorough preanaesthetic check-up including detailed history and a thorough physical examination and routine investigations were carried out.

Special investigations were carried out where and when required. Sitting position was chosen for lumbar puncture. Lumbar puncture was performed using a $25 \mathrm{G}$ needle at the L3-4 inter space using median approach. Paramedian approach was selected when median approach was found difficult.

\section{Observations recorded}

- Blood pressure, Pulse rate, $\mathrm{O}_{2}$ Saturation and episodes of hypotension were recorded.

- 5 minutes from the spinal block

- Every 5 minutes from the spinal block till the end of operation.

All these findings were tabulated and analyzed, and the result was discussed with the reference to the previous studies. 


\section{RESULTS}

Table 1 shows that 25 patients were studied in each group.

Table 2 shows the percentage of patients developing hypotension was maximum in between of patients developing hypotension is maximum in between the age group 31-35 years.

The percentage was $100 \%, 100 \%, 66.66 \%$ and $25 \%$ in Group A, Group B, Group C and Group D respectively. While in between the age group 18-20 the percentage of cases with development of hypotension was minimum i.e. $20 \%, 0 \%, 0 \%, 0 \%$ in Group A, Group B, Group C and Group D respectively (Table 2).
Table 1: Number of cases and different types of I.V. fluid loading used in each group.

\begin{tabular}{|c|c|c|c|}
\hline & Types of I.V. fluids & No. of cases & $\%$ \\
\hline $\begin{array}{l}\text { Group } \\
\text { A }\end{array}$ & $\begin{array}{l}\text { Ringer's lactate } \\
\text { (Crystalloid group) }\end{array}$ & 25 & 25 \\
\hline $\begin{array}{l}\text { Group } \\
\text { B }\end{array}$ & $\begin{array}{l}\text { Haes-steril (Colloid } \\
\text { Group) }\end{array}$ & 25 & 25 \\
\hline $\begin{array}{l}\text { Group } \\
\text { C }\end{array}$ & $\begin{array}{l}\text { Ephedrine infusion } \\
\text { with Ringer's lactate } \\
\text { (Crystalloid } \\
\text { vasopressor group) }\end{array}$ & 25 & 25 \\
\hline $\begin{array}{l}\text { Group } \\
\text { D }\end{array}$ & $\begin{array}{l}\text { Ephedrine infusion } \\
\text { with Haes-steril } \\
\text { (Colloid vasopressor } \\
\text { group) }\end{array}$ & 25 & 25 \\
\hline
\end{tabular}

Table 2: Cases of hypotension in different age groups in each group.

\begin{tabular}{|c|c|c|c|c|c|c|c|c|c|c|c|c|}
\hline \multirow[b]{2}{*}{$\begin{array}{l}\text { Age } \\
\text { Group }\end{array}$} & \multicolumn{2}{|c|}{ Group A } & \multicolumn{4}{|c|}{ Group B } & \multicolumn{3}{|c|}{ Group C } & \multicolumn{3}{|c|}{ Group D } \\
\hline & $\begin{array}{l}\text { Total } \\
\text { no. of } \\
\text { cases }\end{array}$ & $\begin{array}{l}\text { No. of cases } \\
\text { developing } \\
\text { hypotension }\end{array}$ & $\%$ & $\begin{array}{l}\text { Total } \\
\text { no. of } \\
\text { cases }\end{array}$ & $\begin{array}{l}\text { No. of cases } \\
\text { developing } \\
\text { hypotension }\end{array}$ & $\%$ & $\begin{array}{l}\text { Total } \\
\text { no. of } \\
\text { cases }\end{array}$ & $\begin{array}{l}\text { No. of cases } \\
\text { developing } \\
\text { hypotension }\end{array}$ & $\%$ & $\begin{array}{l}\text { Total } \\
\text { no. of } \\
\text { cases }\end{array}$ & $\begin{array}{l}\text { No. of cases } \\
\text { developing } \\
\text { hypotension }\end{array}$ & $\%$ \\
\hline $18-20$ & 5 & 1 & 20 & 3 & 0 & 0 & 3 & 0 & 0 & 3 & 0 & 0 \\
\hline $21-25$ & 11 & 11 & 90.9 & 9 & 4 & 44.49 & 10 & 2 & 20 & 10 & 1 & 10 \\
\hline $26-30$ & 8 & 7 & 87.5 & 12 & 8 & 66.66 & 9 & 5 & 55.53 & 8 & 1 & 12.5 \\
\hline $31-35$ & 1 & 1 & 100 & 1 & 1 & 100 & 3 & 2 & 66.66 & 4 & 1 & 25 \\
\hline
\end{tabular}

Table 3: Different types of indications for caesarean section in each group.

\begin{tabular}{|llllllllll|}
\hline Name of indication & Group A & & Group B & \multicolumn{1}{c}{ Group C } & Group D \\
\hline & No. of cases & \% & No. of cases & \% & No. of cases & \% & No. of cases & \% \\
\hline Foetal distress & 11 & 44 & 12 & 48 & 13 & 52 & 12 & 48 \\
\hline Cepholopelvic disproportion & 2 & 8 & 2 & 8 & 3 & 12 & 2 & 8 \\
\hline Obstructed labor & 3 & 12 & 3 & 12 & 2 & 8 & 3 & 12 \\
\hline Scar tenderness & 8 & 32 & 7 & 28 & 6 & 24 & 8 & 32 \\
\hline Hand prolapse & 1 & 4 & 1 & 4 & 1 & 4 & 0 & 0 \\
\hline
\end{tabular}

Table 3 shows that maximum number of caesarean sections here performed for the indication of foetal distress which is seen in $44 \%, 48 \%, 52 \%$, and $48 \%$ in Group A, Group B, Group C and Group D respectively.

This is followed by scar tenderness and obstructed labor. Minimum numbers of cases were operated for hand prolapsed (Table 3).

Table 4 shows that in Group A maximum number of patients developed hypotension during 11-20 minutes duration which is $13(61.9 \%)$ followed by $5(23.8 \%)$ patients during first 10 minutes.

While minutes patients developed hypotension during 2130 and 31-40 minutes duration which was $1(4.76 \%)$ and $2(9.54 \%)$ respectively.
Table 4: Time of significant fall in systolic arterial pressure in Group A.

\begin{tabular}{|lll|}
\hline $\begin{array}{l}\text { Time elapsed after } \\
\text { spinal block in } \\
\text { minutes }\end{array}$ & $\begin{array}{l}\text { No. of cases } \\
\text { developing } \\
\text { hypotension }\end{array}$ & $\%$ \\
\hline Upto 10 & 5 & 23.8 \\
\hline $11-20$ & 13 & 61.9 \\
\hline $21-30$ & 1 & 4.76 \\
\hline $31-40$ & 2 & 9.54 \\
\hline $41-50$ & 0 & 0 \\
\hline
\end{tabular}

Table 5 shows that in Group B, maximum numbers of patients developed hypotension during 11-20 minutes duration which was $9(69.23 \%)$ followed by 2 patients (15.39\%) each during first 10 minutes and 21-30 minutes duration. 
Table 5: Time of significant fall in systolic arterial pressure in Group B.

\begin{tabular}{|lll|}
\hline $\begin{array}{l}\text { Time elapsed after } \\
\text { spinal block in } \\
\text { minutes }\end{array}$ & $\begin{array}{l}\text { No. of cases } \\
\text { developing } \\
\text { hypotension }\end{array}$ & $\%$ \\
\hline Upto 10 & 2 & 15.38 \\
\hline $11-20$ & 9 & 69.23 \\
\hline $21-30$ & 2 & 15.39 \\
\hline $31-40$ & 0 & 0 \\
\hline $41-50$ & 0 & 0 \\
\hline
\end{tabular}

Table 6: Time of significant fall in systolic arterial pressure in Group C.

\begin{tabular}{|lll|}
$\begin{array}{l}\text { Time elapsed after } \\
\text { spinal block in } \\
\text { minutes }\end{array}$ & $\begin{array}{l}\text { No. of cases } \\
\text { developing } \\
\text { hypotension }\end{array}$ & $\%$ \\
\hline Upto 10 & 5 & 55.55 \\
\hline $11-20$ & 3 & 33.33 \\
\hline $21-30$ & 1 & 11.12 \\
\hline $31-40$ & 0 & 0 \\
\hline $41-50$ & 0 & 0 \\
\hline
\end{tabular}

Table 6 shows that in Group C, maximum number of patients developed hypotension during first 10 minutes which was $5(55.55 \%)$ followed by $3(33.33 \%)$ and 1 $(11.12 \%)$ patient during $11-20$ and $21-30$ minutes duration.

Table 7: Time of significant fall in systolic arterial pressure in Group D.

\begin{tabular}{|lll|}
\hline $\begin{array}{l}\text { Time elapsed after } \\
\text { spinal block in } \\
\text { minutes }\end{array}$ & $\begin{array}{l}\text { No. of cases } \\
\text { developing } \\
\text { hypotension }\end{array}$ & $\%$ \\
\hline Upto 10 & 2 & 66.77 \\
\hline $11-20$ & 1 & 33.23 \\
\hline $21-30$ & 0 & 0 \\
\hline $31-40$ & 0 & 0 \\
\hline $41-50$ & 0 & 0 \\
\hline
\end{tabular}

Table 7 shows that in Group D, out of 3 patients who developed hypotension, minimum patients developed hypotension in first 10 minutes, which are $2(66.77 \%)$. Only 1 patient $(33.23 \%)$ developed hypotension in $11-20$ minutes duration.

Figure 1 show that maximum patients designed hypotension in A-Crystalloid group i.e. 21 (84\%) and the minimum patients, which developed hypotension, was in D-colloid vasopressor group i.e. 3 (12\%), while was Bcolloid group 13 patients $(52 \%)$ and in crystalloid vasopressure group 9 patients $(36 \%)$ developed hypotension.

Figure 2 shows that there was a significant fall in the mean systolic blood pressure throughout the study period in Group A patients, compared to the baseline values. In
Group B significant decrease has been during 15 and 20 minutes of the study compared to the baseline values. While in Group C and D the decrease from the baseline values was not found to be significant.

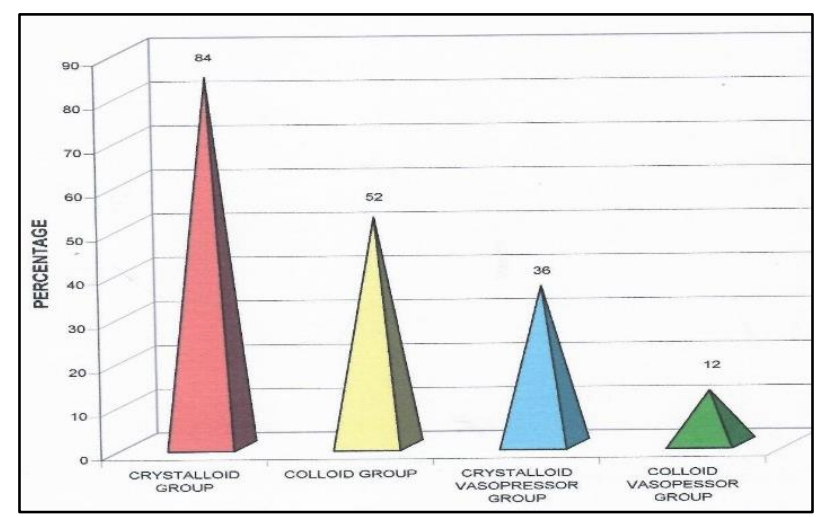

Figure 1: Incidence of hypotension in different groups.

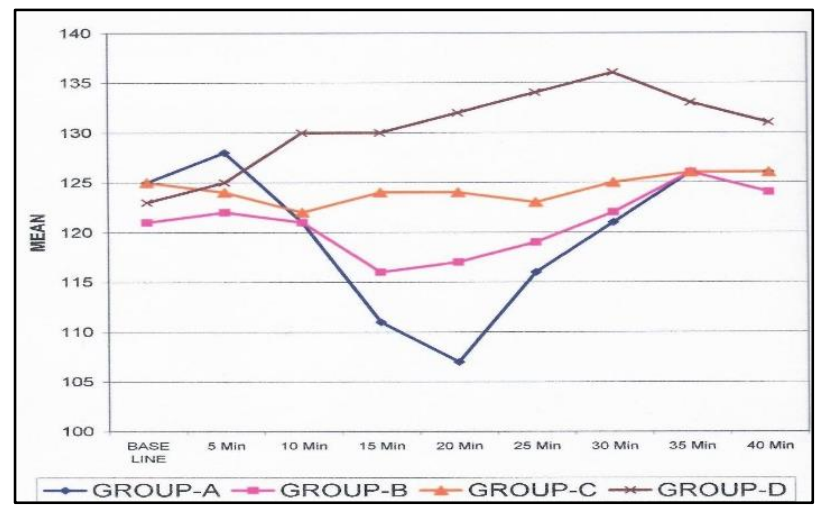

Figure 2: Mean systolic blood pressure in each group.

Figure 3 show that there was a significant rise in the mean pulse rate throughout the study period in Group D patients, compared to the baseline values. In Group C significant increase has been seen during 20 to 25 minutes of the study compared to the baseline values. While in Group A and B the increase was comparable as the baseline values.

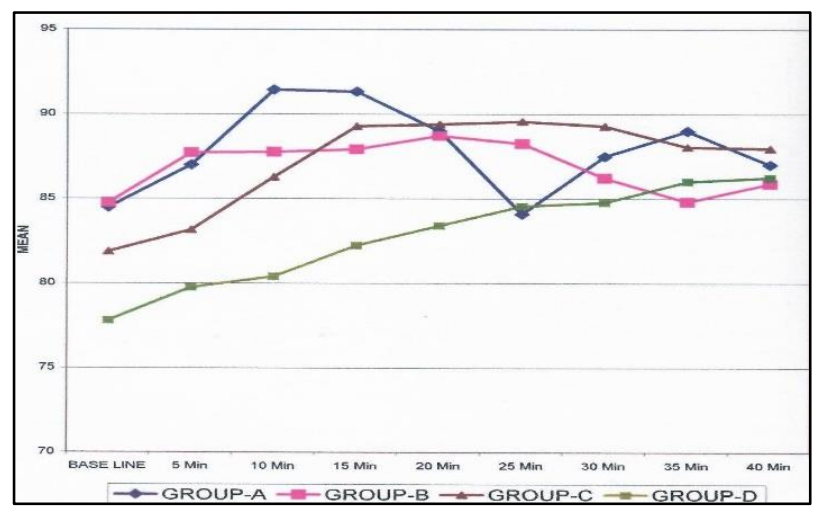

Figure 3: Mean pulse rate in each group. 
Table 8: Hypotension and its management in different groups.

\begin{tabular}{|lllll|}
\hline & Group & $\begin{array}{l}\text { Group } \\
\text { B }\end{array}$ & $\begin{array}{l}\text { Group } \\
\text { C }\end{array}$ & $\begin{array}{l}\text { Group } \\
\text { D }\end{array}$ \\
\hline $\begin{array}{l}\text { No. of } \\
\text { hypotensive } \\
\text { patients }\end{array}$ & 21 & 13 & 9 & 3 \\
$\begin{array}{l}\text { No. of episodes } \\
\text { of hypotension }\end{array}$ & 37 & 22 & 10 & 4 \\
\hline $\begin{array}{l}\text { (\%) of patients } \\
\text { managed by }\end{array}$ & 8 & 7 & 6 & 2 \\
$\begin{array}{l}\text { I.V. fluids only } \\
\text { No. of boluses } \\
\text { of I.V. fluids }\end{array}$ & 20 & 14 & 10 & 3 \\
\hline $\begin{array}{l}\text { (\%) of patients } \\
\text { requiring 6 mg } \\
\text { ephedrine }\end{array}$ & 13 & 6 & 3 & 1 \\
\hline $\begin{array}{l}\text { No. of bolus of } \\
6 \text { mg ephedrine }\end{array}$ & 14 & 6 & 3 & 1 \\
\hline
\end{tabular}

Table 8 shows that 21 patients in Group A, 13 patient in Group B, 9 patient in Group C and only 3 patient in Group B had hypotension following the spinal block, and the difference among the groups is statistically significant. I.V. fluids alone could reverse hypotension in 8 patients in Group A, 7 patients in Group B, 6 patients in Group $C$ and 2 patients in Group D. 13 patients in Group A, 6 patients in Group B, 3 patients in Group C and only 1 patient in Group D could not be managed by I.V. fluids alone and had to be treated with $6 \mathrm{mg}$ bolus of ephedrine for reversal of hypotension. The total number of hypotensive episodes and the use of additional boluses of I.V. fluids and $6 \mathrm{mg}$ ephedrine were maximum in Group A followed by Group B and least in Group D.

Table 9: Incidence of bradycardia, nausea and vomiting and reactive hypotension in each group intra-operatively.

\begin{tabular}{|lllll|} 
& Group & Group & Group & Group \\
& A & B & C & D \\
\hline Bradycardia & 2 & 2 & 1 & 1 \\
\hline $\begin{array}{l}\text { Nausea and } \\
\text { vomiting }\end{array}$ & 6 & 3 & 2 & 1 \\
\hline $\begin{array}{l}\text { Reactive } \\
\text { hypotension }\end{array}$ & 1 & 1 & 5 & 7 \\
\hline
\end{tabular}

Table 9 show that incidence of nausea and vomiting were maximum in Group A patients followed by Group B and Group C and least in Group D. The incidence of reactive hypotension was maximum in Group $\mathrm{D}$ followed by Group $\mathrm{C}$ and only 1 patient had reactive hypotension in Group A and Group B each. Bradycardia was found in 2 patients is Group A and Group B each and only 1 patient in Group C and Group D each.

Table 10 shows mean systolic blood pressure did no differ much from the baseline values in Group B, Group $\mathrm{C}$ and Group D while in Group A there was a decrease in mean systolic pressure at 12 hours post operative compared to the base line values. Pain was the major complain of all patients irrespective of the groups divided, followed by backache and chest pain. However, maximum patients who did not complained of any symptoms were of Group B and Group C. Incidence of vomiting was seen in 3 patients of Group A only.

Table 10: Postoperative monitoring in each group with associated complains.

\begin{tabular}{|lll|ll|} 
& Group & Group & Group & Group \\
& A & B & C & D \\
\hline Mean systolic & 119 & 123 & 129 & 124 \\
pressure (SD) & 6.26 & 8.48 & 6.23 & 8.83 \\
\hline Pain & 10 & 12 & 12 & 11 \\
\hline Backache & 6 & 8 & 6 & 6 \\
\hline Chest pain & 2 & 1 & 2 & 1 \\
\hline Headache & 1 & - & - & 1 \\
\hline Vomiting & 3 & 1 & - & - \\
\hline No complaints & 3 & - & 5 & 6 \\
\hline
\end{tabular}

\section{DISCUSSION}

The study was done on 100 patients, divided into 4 groups of 25 each, undergoing emergency caesarean sections. After the induction of subarachnoid block for caesarean section, hypotension developed which can be minimized by the use of judicious use of vasopressor agent. It has been shown by Corke BC et al. that the percentage decrease in placental perfusion is related to the percentage reduction in maternal arterial pressure and not to absolute reduction in pressure. ${ }^{11}$ For the purpose of this study, hypotension was designed as a decrease in arterial pressure greater than $20 \%$ from baseline systolic pressure or decrease less than $100 \mathrm{~mm} \mathrm{Hg}$.

Drugs used for spinal anaesthesia in caesarean section are mainly local anaesthetics of either the amide or ester class, based on the link existent between the amine and aromatic arms. ${ }^{12}$ The aromatic arm accounts for lipidsolubility, which in turn determines its potency, that is, the more lipid soluble the drug, the faster the time of onset and the greater its ability to penetrate through nerve sheaths with consequent increase in potency. ${ }^{12}$ Also, the ability to bind plasma proteins is an indicator of the duration of action of the drug. Local anaesthetics such as bupivacaine, ropivacaine, levobupivacaine, chloroprocaine, lidocaine, and tetracaine have been used for caesarean operations, in combination usually with opioids such as fentanyl or its derivatives, or morphine. ${ }^{4,7}$

Bupivacaine, also known as Marcaine, is an amide anaesthetic administered at $10 \mathrm{mg}$ to $15 \mathrm{mg}$ in $0.5 \%$ to $0.75 \%$ concentrations, and is more commonly used for spinal block in caesarean procedures. ${ }^{6,8,13}$ Although its onset of action is slow, lasting about five to 10 minutes and dependent on baricity, the incidence of hypotension is low. ${ }^{14}$ Bupivacaine can also be obtained in a hyperbaric $7.5 \%$ solution. ${ }^{14-16}$ It is popularly used due to a longer duration of action and good quality of motor block 
compared to tetracaine, and has been associated with dose-dependent cardiac toxicity. $., 13,17$

Maternal hypotension is the most frequent complication of a spinal anaesthetic for caesarean section with an incidence approaching $100 \%$. Most workers define hypotension as a maternal systolic blood pressure below $70-80 \%$ of baseline recording and/or an absolute value of $<90-100 \mathrm{mmHg}$. The frequent occurrence and rapid onset of hypotension during spinal anaesthesia has encouraged anaesthetists to try and prevent or minimise the associated maternal symptoms of nausea and vomiting during the establishment of the block. Untreated, severe hypotension can also pose serious risks to both mother (unconsciousness, pulmonary aspiration, apnoea or even cardiac arrest) and baby (impaired placental perfusion leading to hypoxia, fetal acidosis and neurological injury. ${ }^{18}$

The groups were comparable in age and physical characteristics. Indications for the caesarean section were comparable in all the 4 groups with majority of them being done for foetal distress. All the 4 groups here similar in sensory block level, time to develop hypotension, mean time to delivery and uterine incision to delivery interval. In the present study the evidence of hypotension in the groups studied was $84 \%$ in Group A, $53 \%$ in Group B, 36\% in Group C and 12\% in Group D. Study conducted by Gajraj et al. showed that the incidence of hypotension was $55 \%$ in the crystalloid group and $22 \%$ in the Ephedrine infusion group. ${ }^{19}$ Dahlgren $G$ et al found that Dextran reduced the incidence of overall hypotension was from $85 \%$ to $66 \%$ compared to Ringer's lactate. ${ }^{20}$ Kiran $\mathrm{M}$ et al. studies on the efficacy of Crystalloid preloading the Ephedrine infusion and concluded that $3.33 \%$ patients in Ephedrine infusion group and $43.33 \%$ in Crystalloid group developed hypotension. ${ }^{21}$ Baraka et al. have shown that incidence of hypotension was higher in LR group than in HES group ( $80 \%$ vs. $40 \%)$. $^{22}$

In our study the incidence of hypotension in the Group A is in agreement with Dahlgren $\mathrm{G}$ et $\mathrm{al}^{20}$ and Baraka et $\mathrm{al}^{22}$. But there was disagreement with other authors. This difference in the incidence is probably due to the way in which hypotension is defined and to the changes related to the pregnancy in which blood pressure is measured. The present study supports the findings of Baraka et $\mathrm{al}^{22}$ and Dehlgen $\mathrm{G}$ et $\mathrm{al}^{20}$ which demonstrated a lower incidence of hypotension in parturients undergoing elective caesarean section who were preloaded with 15 $\mathrm{ml} / \mathrm{kg}$ colloid than in those who received double volume of lactated ringer solution. This small volume of colloid can be administered quickly, within $10 \mathrm{~min}$, allowing rapid and effective preloading prior to spinal anaesthesia for caesarean section, which is desirable in urgent situation. The current recommendations limit the maximum dose of HES to $20 \mathrm{ml} / \mathrm{kg} /$ day due to concerns of adverse haematological, immunological, renal and reticuloendothelial function. There is concern that HES might be associated with bleeding diathesis. However, excessive clinical bleeding was not observed in patients. Also, the allergic potential of HES is several times lower than that of gelatins and no adverse reactions to HES occurred in this study.

In the studies conducted by Vercauteren et al., women given ephedrine before or during induction of spinal anaesthesia had a lower incidence of maternal hypotension compared with those not given a vasopressor. ${ }^{23}$ In the present study also, it has been shown that prophylactic ephedrine is more effective for preventing hypotension in healthy parturient undergoing spinal anaesthesia for caesarean section. Critchley et al observed significant increase in heart rate in the ephedrine treated group, which is similar to our findings in the combination group-Group $\mathrm{C}$ and Group D. Reducing the dose of vasopressor in the combination group, could obviate this problem. ${ }^{24}$

\section{CONCLUSION}

In summary, hypotension from central neural blockade results from decreases in systemic vascular resistance and increased venous pooling. No single management strategy is effective in treating hypotension produced by spinal anaesthesia. The prophylaxis and management of hypotension during spinal anaesthesia is primarily aimed at stabilizing cardiac filling by an increase in either blood volume or to counteract vasodilatation. Various combinations and volumes of crystalloids and colloid solutions have been used, but none is entirely effective in prevention of hypotension. Venous pooling may be corrected with fluid administration. The effects of crystalloid solutions on central blood volume are less predictable because of transcapillary fluid loss into the extravascular space. In pre-hydrated subject's blood pressure also decreases compared to subject without prophylactic crystalloid infusion, though with some delay.

The study concludes that the combined use of volume preloading to compensate for vasodilatation and vasopressor to counteract arterial dilatation is a very effective method in reducing the incidence, severity and duration of spiral hypotension. The combination group with decreased volume of preload and reduced dose of vasoconstrictor provides better haemodynamic stability when compared to preloading of vasoconstrictors alone. However, we feel that further investigation with tightly controlled studies are required to optimize the combination of preloading and vasoconstrictors, so as to completely eliminate the problem of hypotension associated with spinal anaesthesia.

\section{Funding: No funding sources}

Conflict of interest: None declared

Ethical approval: The study was approved by the Institutional Ethics Committee 


\section{REFERENCES}

1. Jenkins JG, Khan MM. Anaesthesia for caesarean section: a survey in a UK region from 1992 to 2002. Anaesthesia. 2003;58(11):1114-8.

2. Afolabi BB, Lesi FE. Regional versus general anaesthesia for caesarean section. Cochrane Database Syst Rev. 2012 Oct;10:CD004350.

3. Michie AR, Freeman RM, Dutton DA, Howie HB. Subarachnoid anaesthesia for elective caesarean section. Anaesthesia. 1988;43:96-9.

4. Rollins M, Lucero J. Overview of anesthetic considerations for cesarean delivery. Br Med Bull. 2012;101:105-25.

5. Casey WF. Spinal anaesthesia-a practical guide. Update in Anaesthesia. 2000;12:1-7.

6. Ankcorn C, Casey WF. Spinal anaesthesia-a practical guide. Update in Anaesthesia. 1993;3:2-15.

7. Gogarten W. Spinal anaesthesia for obstetrics. Best Pract Res Clini Anaesthesiol. 2003;17:377-92.

8. Grant GJ, Hepner David L, Barss VA. Neuraxial analgesia and anesthesia for labor and delivery: drugs. Available at http:// www.uptodate.com/home 2011. Accessed on 22 November 2017.

9. Mohta M. Ropivacaine: Is it a good choice for spinal anesthesia? J Anaesthesiol, Clin Pharmacol. 2015;31(4):457-458.

10. Luck JF, Fettes PD, Wildsmith JA. Spinal anaesthesia for elective surgery: A comparison of hyperbaric solutions of racemic bupivacaine, levobupivacaine, and ropivacaine. $\mathrm{Br} \mathrm{J}$ Anaesth. 2008;101:705-10.

11. Corke BC, Datta S, Ostheimer GW, Weiss JB, Alper MH. Spinal anaesthesia for caesasean section. The influence of hypotension on neonatal outcome. Anaesthesia. 1982;37:658-62.

12. Becker DE, Reed KL. Essentials of local anesthetic pharmacology. Anesthesia Progress. 2006;53(3):98109.

13. Cousins MJ, Bridenbaugh PO. Neural blockade in clinical anesthesia and management of pain. Lippincott Williams \& Wilkins;1998.

14. Bano F, Sabbar S, Zafar S, Rafeeq N, Iqbal MN, Haider S, et al. Intrathecal fentanyl as adjunct to hyperbaric bupivacaine in spinal anesthesia for caesarean section. JCPSP 2006;16(2):87-90.

15. Roberts FL, Brown EC, Davis R, Cousins MJ. Comparison of hyperbaric and plain bupivacaine with hyperbaric cinchocaine as spinal anaesthetic agents. Anaesthesia. 1989;44:471-4.
16. Karaman S, Kocabas S, Uyar M, Hayzaran S, Firat $\mathrm{V}$. The effects of sufentanil or morphine added to hyperbaric bupivacaine in spinal anaesthesia for caesarean section. Eur J Anaesthesiol. 2006;23:28591.

17. Atalay C, Aksoy M, Aksoy AN, Dogan N, Kürsad H. Combining intrathecal bupivacaine and meperidine during caesarean section to prevent spinal anaesthesia-induced hypotension and other sideeffects. J Int Med Res. 2010;38(5):1626-36.

18. Emmett RS, Cyna AM, Andrew M, Simmons SW. Techniques for preventing hypotension during spinal anaesthesia for caesarean section. Cochrane Database Syst Rev. 2001;(3):CD002251.

19. Sharma SK, Gajraj NM, Sidawi JE. Prevention of hypotension during spinal anaesthesia: a comjparison of intravascular administration of hetastarch versus lactated Ringer's solution. Anaesth Analg. 1997;84:11-4.

20. Dahlgren G, Granath F, Wessel H, Irestedt L. Prediction of hypotension during spinal anesthesia for cesarean section and its relation to the effect of crystalloid or colloid preload. Int J Obstet Anesth. 2007; 16:128-34.

21. Kiran M, Hemant B, Sudhir KE, Prakash CS. Evaluation of preloading and vasoconstrictors as a combined prophylaxis for hypotension during sub arachnoid anaesthesia. Ind J Anaesth. 2004;48(4):299-303.

22. Baraka AS, Taha SK, Ghabach MB, Sibaii AA, Nader AM. Intravascular administration of polymerized gelatin versus isotonic saline for prevention of spinal-induced hypotension. Anesth Analg. 1994;78:301-5.

23. Vercauteren MP, Hoffman, Coppejans HC, Van Steenberge AL, Adriaensen HA. Hydroxyethylstarch compared with modified gelatine as volume preload before spina anaesthesia modified gelatine as volume preload before spinal anaesthesia for caesarean section. Br J Anaesth. 1996;76:731-3.

24. Critchley LAH. Hypotension, subarachnoid block and the elderly patient. Anaesthesia. 1996;51:113943.

Cite this article as: Minj SD, Beck R, Kumar A, Tiwari P, Chandan RK, Sen S. The incidence and management of hypotension in the pregnant parturients undergoing caesarean section following spinal anaesthesia with $0.5 \%$ bupivacaine. Int $\mathbf{J}$ Reprod Contracept Obstet Gynecol 2018;7:1205-11. 